\title{
Research of water control technology for horizontal wells in water-driven reservoirs
}

\author{
Baobing Shang ${ }^{1 *}$, Xiaodong $\mathrm{Han}^{1}$, Shuai $\mathrm{Li}^{2}$, Kouqi $\mathrm{Liu}^{3}$ \\ ${ }^{1}$ Tianjin Branch, China National Offshore Oil Corporation, Tianjin 300459, P. R. China \\ ${ }^{2}$ Department of Earth Science and Engineering, Imperial College, London, the UK \\ ${ }^{3}$ Department of Petroleum Engineering, University of North Dakota, Grand Forks, USA
}

(Received April 6, 2018; revised April 24, 2018; accepted April 25, 2018; available online April 29, 2018)

\section{Citation:}

Shang, B., Han, X., Li, S., Liu, K.

Research of water control technology for horizontal wells in water-driven reservoirs. Advances in Geo-Energy Research, 2018, 2(2): 210-217, doi: 10.26804/ager.2018.02.08.

Corresponding author:

*E-mail: shangbb@cnooc.com.cn

Keywords:

Horizontal well

bottom water reservoir

stinger completion

water control

mathematical model

\begin{abstract}
:
Horizontal wells are widely applied in the Bohai offshore oil fields due to their large oil drainage areas and high yields. However, water coning is a significant problem existing in water-driven reservoirs. To control water coning, this paper introduces a stinger completion method which can be applied in the horizontal wells. Based on the principle of mirror reflection and mass conservation law, a mathematical model coupling fluid flow both in the reservoir and in the horizontal wellbore has been developed. Using the new proposed model, the well production profile and bottom hole flowing pressure distribution along the horizontal well, considering the influence of flowing in the wellbore, are calculated successfully. Moreover, the influence of the stinger completion on the inflow profile is investigated. According to the results of the sensitivity analysis, a 160m' 2-7/8 tubing is designed to be built in the horizontal section. The field-test results show that the stinger completion could be used to improve the wellbore inflow profile and decrease the possibility of water-cut thus increasing the effective enhanced oil recovery.
\end{abstract}

\section{Introduction}

Horizontal wells are one of the most powerful tools to improve well production by increasing the contact areas with reservoir, changing the seepage mode in near well zone, and reducing the seepage resistance (Wolfsteiner et al., 2000; Furui et al., 2002; Khoriakov et al., 2012). More than 30 percent of oil wells in Bohai oil fields produce with horizontal wells, achieving relatively good development results. However, there are still some problems in the application of horizontal wells, such as the uneven inflow along the horizontal section, water coning, and high cost for water plugging (Shuai et al., 2012; Wang et al., 2016). Nowadays, part of horizontal wells are experiencing high water cut period in Bohai oil fields and the effective water control technologies need to be developed.

In order to reduce the water cut of horizontal wells, several mechanical and chemical water control technologies have been employed in Bohai. Water control can be realized through several methods, including: (1) adjusting the net production pressure differential along the horizontal section to uniform oil-water plane propulsion; (2) building artificial barriers or extracting water for cone control to slow down or inhibit water coning; (3) injecting chemical reagents for water plugging after water breakthrough (Xiong et al., 2009; Li et al., 2011; Sierra et al., 2011; Fu et al., 2016; Abdulmohsin et al., 2017; $\mathrm{Ma}$ and Yi, 2017). Based on the research of stinger completion by other scholars (Brekke and Lien, 1994; Permadi et al., 1997; Jansen et al., 2002; Jansen, 2003), stinger completion technology which is suitable for producing wells is studied in this paper, aiming to reduce water cut and improve final oil recovery.

For horizontal wells, producing pressure drop is usually greater in the heel (Augustine, 2002; Hill and Zhu, 2006; Gomez et al., 2014). This will cause non-uniform inflow along the wellbore length direction, bringing the water coning issues (Augustine et al., 2006; Wang et al., 2010). With stinger completion technology, one thinner tubing is inserted into the conventional horizontal section. Besides, the annulus between small diameter tubing and borehole is sealed by packer, as shown in Fig. 1. Thus the simple borehole flow in the wellbore is divided into three parts: (1) flow in the annulus, (2) flow in the borehole, and (3) flow inside the central pipe (Zhang 


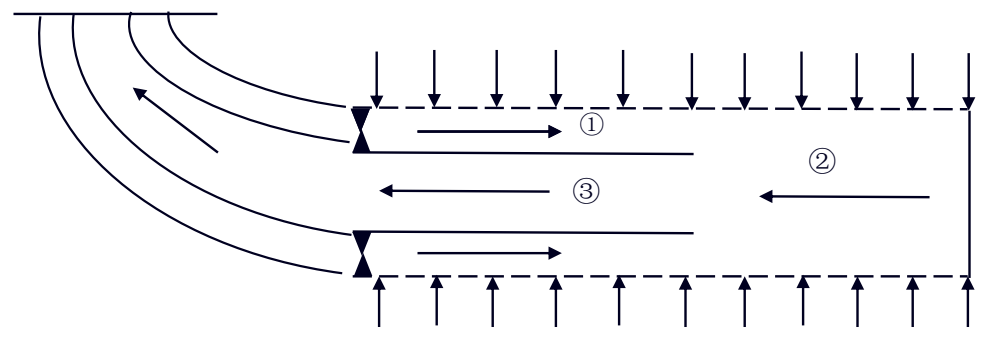

Fig. 1. Schematic of common Stinger Completion.

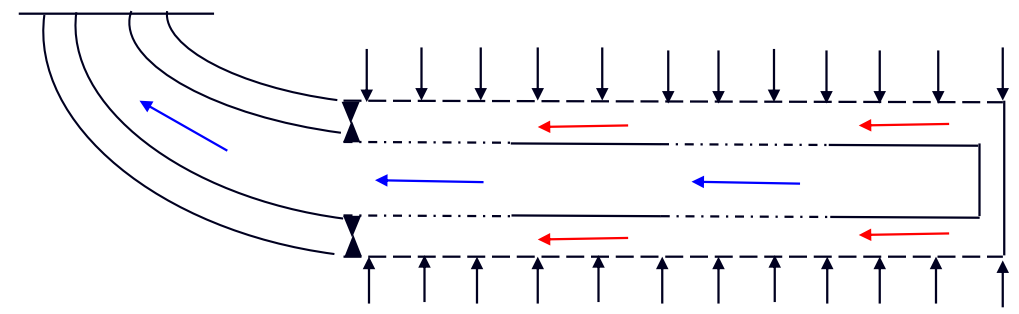

Fig. 2. Schematic of improved stinger Completion.

et al., 2009). Under this circumstance, the large pressure drop difference in specific location is reduced, and the inflow profile is more uniform along the horizontal section, which is useful to prevent the rapid rise of water cut.

Common stinger completion shows the limited effect for some wells. Thus, an improved stinger completion technology is developed in this study. This technology considers the influences of actual well trajectory, inflow profile, and water ridge shape into designing the center pipe structure and length. In horizontal section with low resistance and large inflow, a part of blind pipe is equipped in the section. While in other parts of the well, perforated tube is set. This type of center pipe is more effective to solve the problem of bottom water coning in some specific wells (Fig. 2).

\section{Coupled model of stinger completion}

\subsection{Reservoir percolation model}

In the paper, flowing fluid is assumed to be single-phase incompressible Newtonian liquid, and the entire flow system is isothermal. According to the mathematical model proposed by Liu' group and other scholars (Liu et al., 1999; Liu et al., 2000; Wang et al., 2012; Naderi et al., 2015), if the horizontal well is regarded as a line sink in unbounded formation, as shown in Fig. 3, then the potential distribution of the formation under steady-state seepage can be expressed as:

$$
\phi(x, y, z)= \begin{cases}-\frac{Q}{4 \pi L} \ln \frac{x-x_{1}}{x-x_{2}}+C \quad\left(y=0, z=z_{w}\right) \\ -\frac{Q}{4 \pi L} \ln \frac{r_{2}+\left(x_{2}-x\right)}{r_{1}+\left(x_{1}-x\right)}+C \quad \text { (other conditions) }\end{cases}
$$

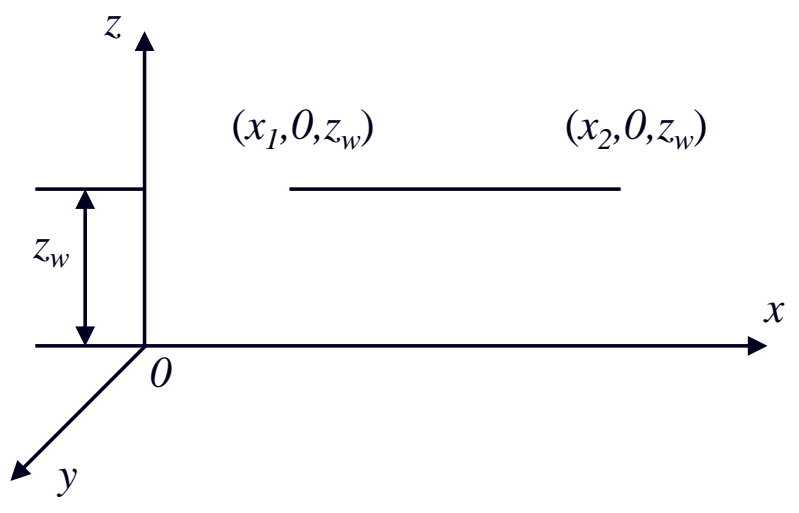

Fig. 3. Scheme of a horizontal well in an unbounded reservoir.

In the equation,

$$
\begin{aligned}
& r_{1}=\sqrt{\left(x_{1}-x\right)^{2}+y^{2}+\left(z_{w}-z\right)^{2}} \\
& r_{2}=\sqrt{\left(x_{2}-x\right)^{2}+y^{2}+\left(z_{w}-z\right)^{2}}
\end{aligned}
$$

For bottom water drive reservoir, the bottom is a constant pressure boundary and the top is a closed boundary, as shown in Fig. 4. With mirror reflection principle, the bounded formation can be converted into infinite (Johansen and Khoriakov, 2007; Hasan and Kabir, 2009; Amini and Valkó, 2010). If dividing the horizontal well with the length of $L$ into $N$ sections, then the potential $\phi_{i}$ of any point in the formation caused by segment $i$ is as follow: 


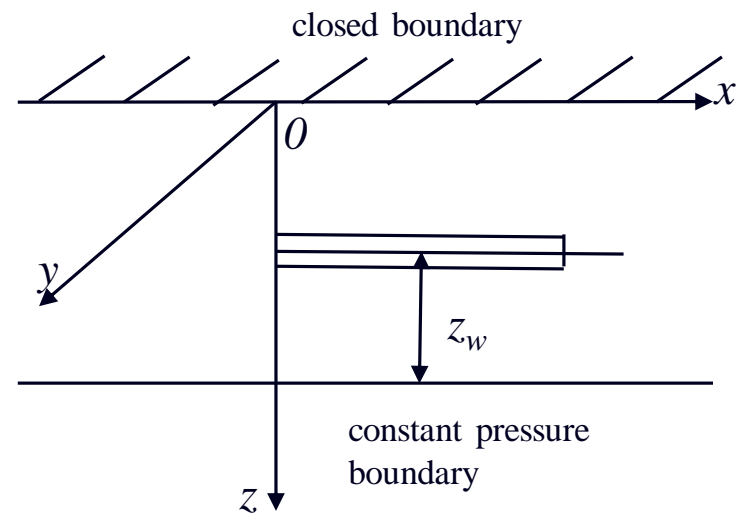

Fig. 4. Horizontal well in bottom water reservoir.

$$
\begin{aligned}
& \phi_{i}(x, y, z)= \\
& -\frac{q_{i}}{4 \pi L_{i}} \sum_{n=-\infty}^{\infty}\left(\begin{array}{l}
\xi_{i}\left(4 n h+z_{w}, x, y, z\right) \\
+\xi_{i}\left(4 n h+2 h-z_{w}, x, y, z\right) \\
-\xi_{i}\left(4 n h-z_{w}, x, y, z\right) \\
-\xi_{i}\left(4 n h-2 h-z_{w}, x, y, z\right)
\end{array}\right)+C_{i}
\end{aligned}
$$

In the equation,

$$
\begin{gathered}
\xi_{i}\left(\eta_{n}, x, y, z\right)=\ln \frac{r_{n 1}+r_{n 2}+L_{i}}{r_{n 1}+r_{n 2}-L_{i}} \\
r_{1}=\sqrt{\left(x_{1 i}-x\right)^{2}+y^{2}+\left(\eta_{n}-z\right)^{2}} \\
r_{2}=\sqrt{\left(x_{2 i}-x\right)^{2}+y^{2}+\left(\eta_{n}-z\right)^{2}}
\end{gathered}
$$

According to the superposition principle of potential, the potential generated by whole horizontal well in the formation is:

$$
\begin{gathered}
\phi=\sum_{i=1}^{N} \phi_{i}+C=-\sum_{i=1}^{N} \frac{q_{i} k}{4 \tau \mu} \varphi_{i}+C \\
\varphi_{i}=\frac{1}{L_{i}} \sum_{n=-\infty}^{\infty}\left(\begin{array}{l}
\xi_{i}\left(4 n h+z_{w}, x, y, z\right) \\
+\xi_{i}\left(4 n h+2 h-z_{w}, x, y, z\right) \\
-\xi_{i}\left(4 n h-z_{w}, x, y, z\right) \\
-\xi_{i}\left(4 n h-2 h-z_{w}, x, y, z\right)
\end{array}\right)+C_{i}
\end{gathered}
$$

Supposing that the pressure at the center point of $j$ segment is $P_{w j}$, and the potential in the middle point of $j$ segment caused by the $i$ segment is $\phi_{i j}$, then the upper formula can be changed to:

$$
\sum_{i=1}^{N} \lambda q_{i}\left(\varphi_{i j}-\varphi_{i e}\right)=P_{e}-P_{w j}+\rho g\left(Z_{e}-Z_{w}\right)
$$

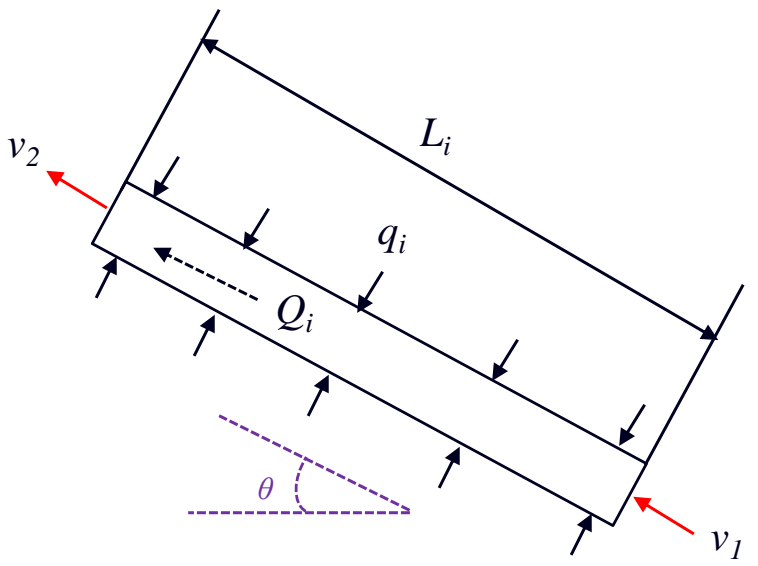

Fig. 5. Flow model of the horizontal section.

\subsection{Flowing model in the horizontal wellbore}

For horizontal wells, there are four types of pressure drops in the wellbore: frictional, accelerating, gravitational and mixing pressure drop (Vicente et al., 2000; Souza, 2014; Luo et al., 2015; Adesina et al., 2016). Fig. 5 shows the flow model of the horizontal section. According to the principle of energy conservation and momentum theorem, the pressure drop of each segment $\Delta P_{w f i}$ can be calculated as follows:

$$
\Delta P_{w f i}=\rho g \sin \theta L_{i}+\frac{8 f \rho Q_{i}^{2} q_{i}}{\pi^{2} D^{5}}+\frac{32 f \rho Q_{i} q_{i}}{\pi^{2} D^{4}}+\frac{16 f \rho q_{i}^{2}}{\pi^{2} D^{4}}
$$

\subsection{Coupled model of stinger completion}

For actual production process, the reservoir seepage and flow in the wellbore are mutually influenced. When calculating the actual inflow profile and the bottom hole flowing pressure distribution, both of the two flowing processes need to be considered (Cheng and Lan, 2002; Ouyang and Huang, 2005; Szanyi et al., 2018). The complete calculation process is shown in Fig. 6. In the coupled model, the flowing pressure drop of the horizontal section with central tubing is increased compared with conventional condition, the inflow profile will be different at last.

\section{Example calculation and analysis}

\subsection{Production status of the oilfield}

$\mathrm{C}$ oilfield is a typical edge-bottom water reservoir with adequate energy. It develops by natural water drive. Because of the low avoid water height and large oil-water flow ratio, edge-bottom water breakthrough is easy to happen. The oil wells in this oilfield are characterized of short water-free oil period and low oil recovery. The water cut reached $80 \%$ after the oilfield produced 2 years. Currently, the total water cut is about $95 \%$. With the increase of water content, the liquid production of the oilfield goes up rapidly. However, due to the 


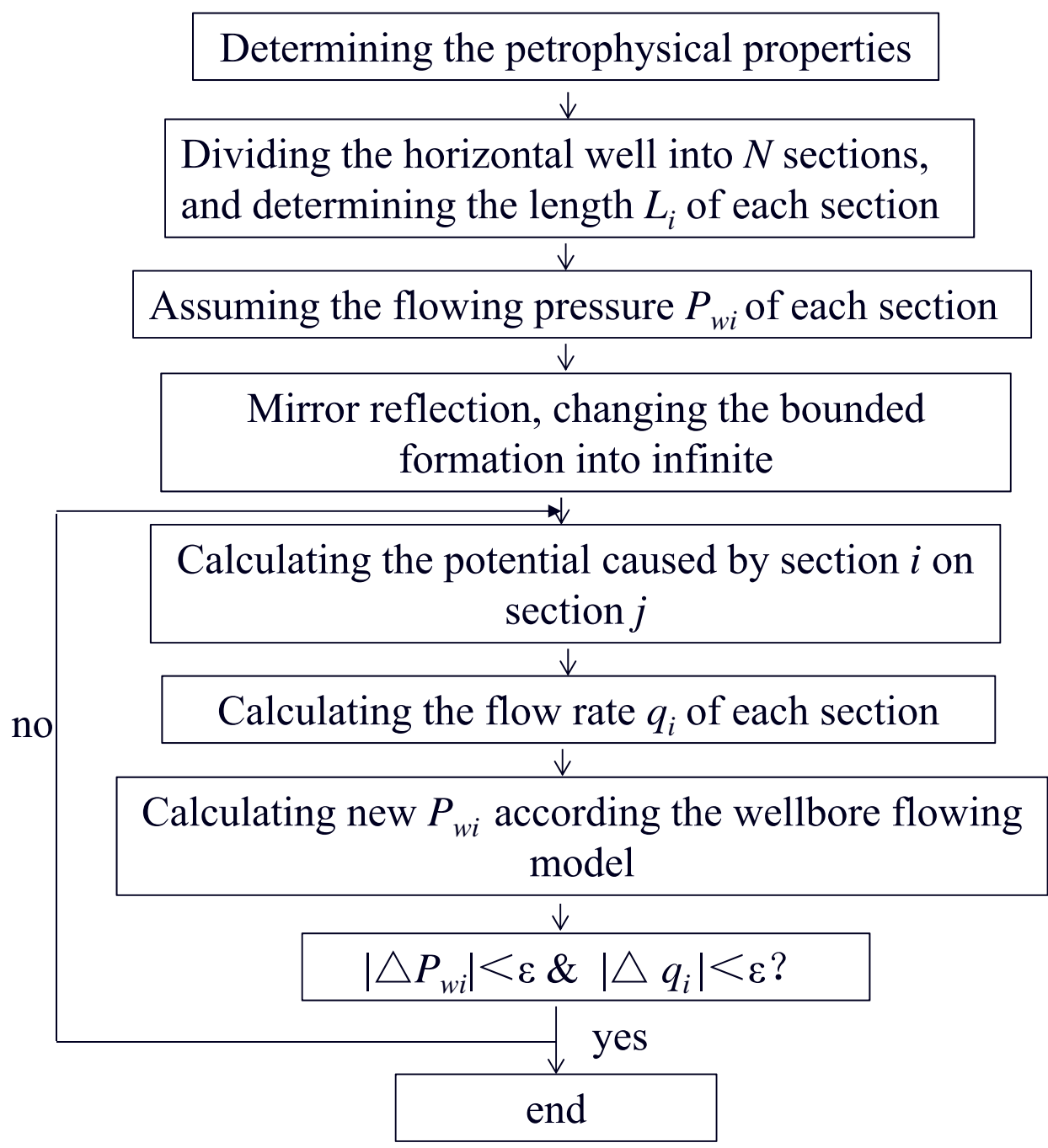

Fig. 6. Flowchart of calculation process.

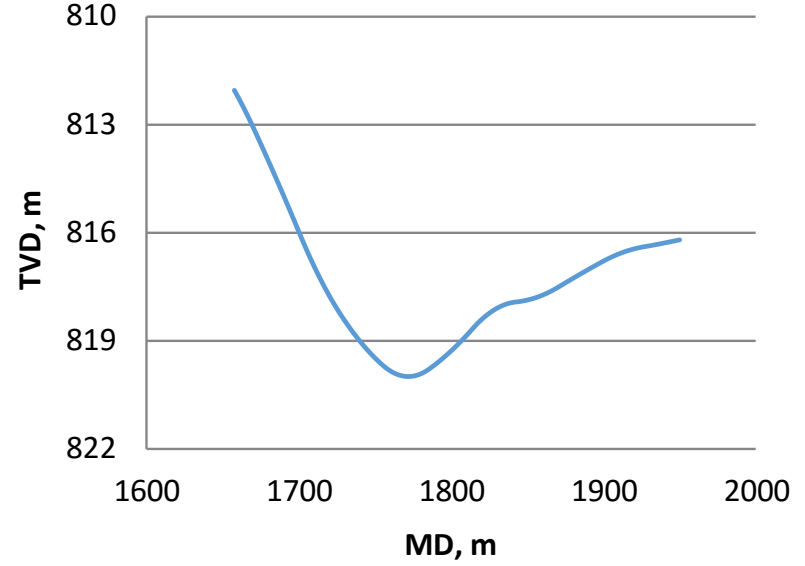

Fig. 7. Well trajectory of the horizontal section.

restriction of platform handling capacity, the total liquid pro- duction of the oilfield is limited to a finite value. The stable production of the oilfield faces a great challenge.

The target well is a horizontal well in C Oilfield with bottom water. The main oil layer is Minghuazhen Group. When the well normally produced, the water cut gradually rise to about $40 \%$. After two years, the water content rapidly increased to about $98 \%$ due to water breakthrough. To maintain oil production, the production pressure differential was increased to raise the liquid yield. Several measures were applied to reduce the water cut but the result was not satisfactory. In order to reduce water cut, stinger completion technology was applied in this well.

\subsection{Petrophysical properties of study borehole}

The basic data about reservoir fluid and this well are shown in Table 1. It is obvious that this is a typical heavy oilfield. The real well track of the horizontal section is shown in Fig. 7, which shows that the buried depth of horizontal sections varies, indicating that the avoid water heights are different along the horizontal section. The well is completed by open-hole gravel 
Table 1. Petrophysical properties of the target well.

\begin{tabular}{ll}
\hline The reservoir and well characteristics & Value \\
\hline Formation oil density $\left(\mathrm{g} / \mathrm{cm}^{3}\right)$ & 0.98 \\
Formation oil viscosity $(\mathrm{mPa} \cdot \mathrm{s})$ & 432 \\
Original formation pressure $(\mathrm{MPa})$ & 7.8 \\
Formation temperature $\left({ }^{\circ} \mathrm{C}\right)$ & 59 \\
Reservoir buried depth $(\mathrm{m})$ & 817 \\
Reservoir thickness $(\mathrm{m})$ & 15.4 \\
Average permeability $(\mathrm{md})$ & 5400 \\
Inner diameter of sieve tube $(\mathrm{mm})$ & 124 \\
Horizontal length $(\mathrm{m})$ & 287 \\
\hline
\end{tabular}

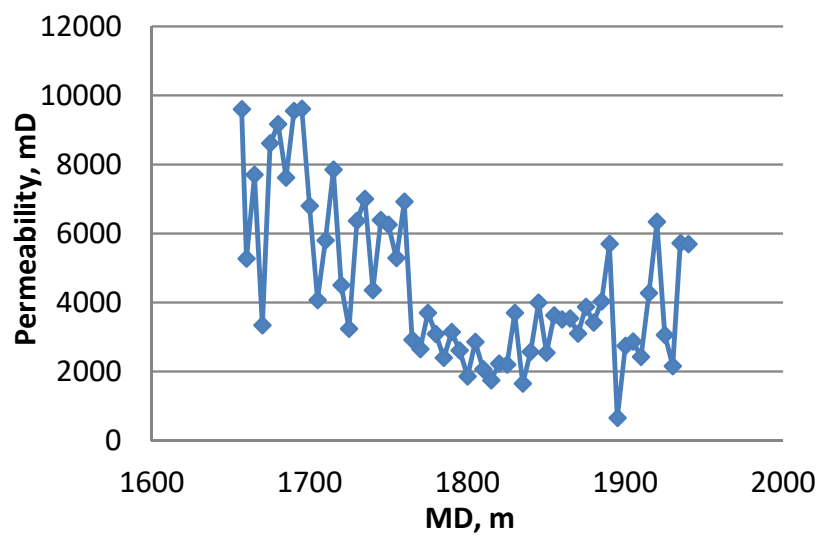

Fig. 8. Permeability distribution along horizontal section.

packing, with the horizontal length of $287 \mathrm{~m}$. The inner diameter of the sieve tube is $4.892 \mathrm{in}$. The permeability along the wellbore is shown in Fig. 8. It shows the reservoir permeability of the heel is relatively high, while the permeability of the figure part is low. This will aggravate the inhomogeneity of the inflow profile.

\subsection{Design and analysis of stinger completion}

With the new mathematical model derived in the paper, the liquid producing profile and flowing pressure profile along the horizontal section under conventional producing condition were calculated, as shown in Figs. 9 and 10. Calculating results indicated that the heeling section contributed more liquid compared to other sections, and the liquid production of unit length showed positive correlation with the distribution of permeability. Because the middle section of the well had the maximum vertical depth, the breakthrough time of bottom water is shortest at this point, as shown in Fig. 11.

During the design of stinger completion, several calculations were made to optimize the setting length of central tube. Besides, the improved stinger completion technology was also considered in the project. In the calculating model, one 2-7/8 tubing with inner diameter of $62 \mathrm{~mm}$ was applied, as shown

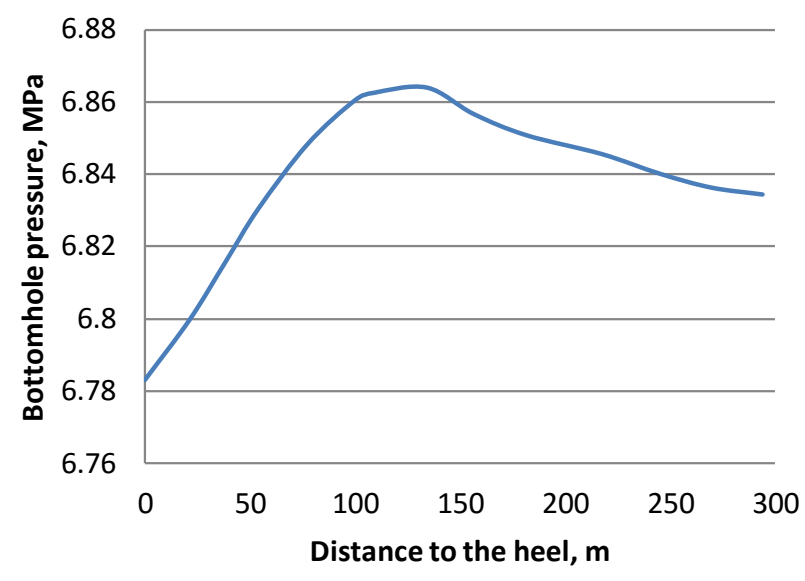

Fig. 9. Distribution of bottom hole pressure.

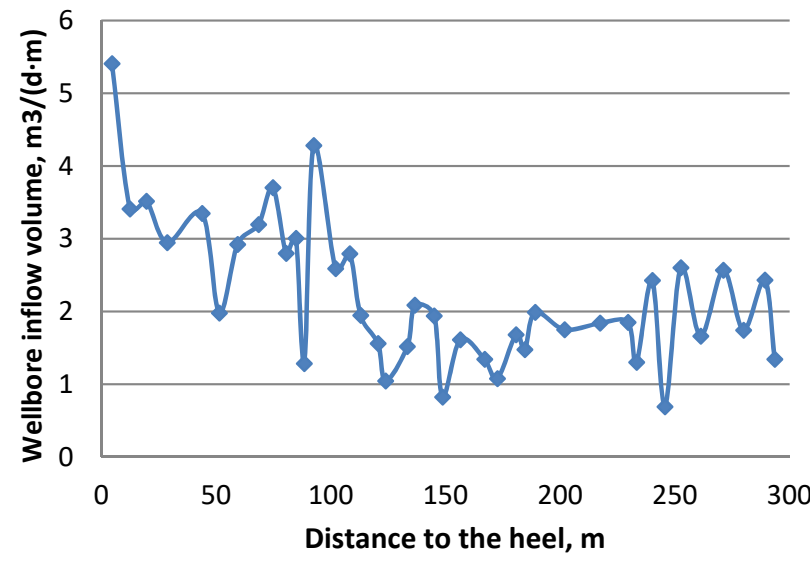

Fig. 10. Predicted fluid producing profile.

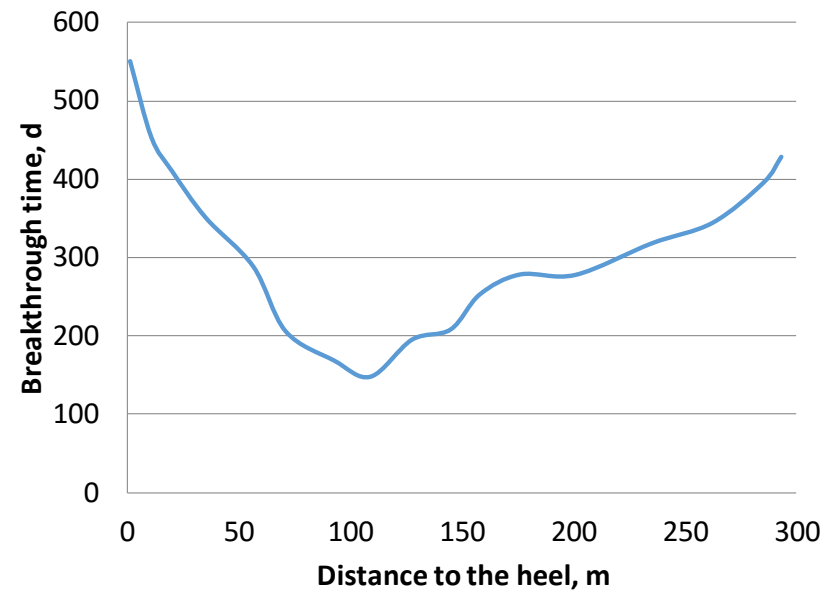

Fig. 11. Breakthrough time of bottom water.

in Fig. 12. The calculation results indicated that, the liquid contribution of the horizontal section which was equipped with central tube was reduced, thus the total liquid production of the well decreased, as shown in Table 2. This was helpful to reduce the water cut of the well. At last, the third project was 


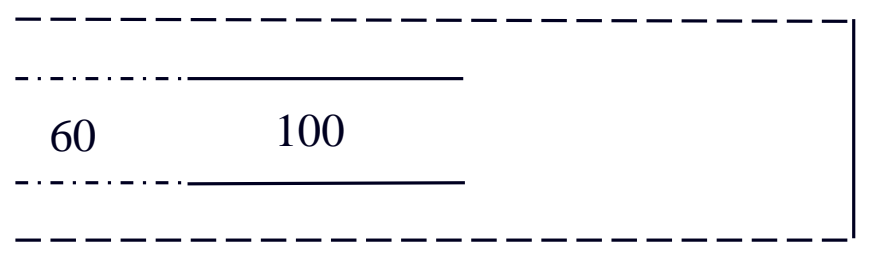

(a)

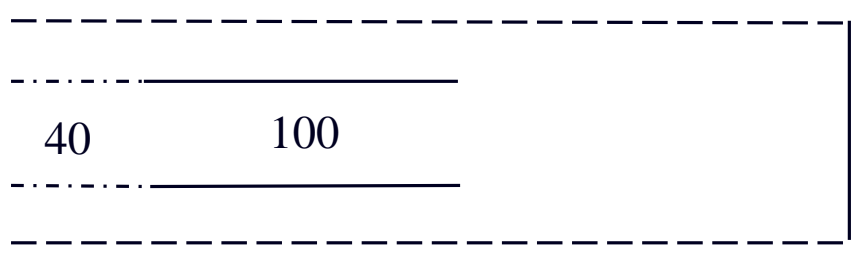

(b)

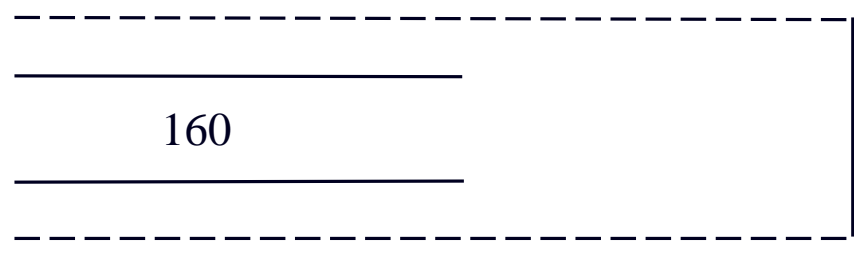

(c)

Fig. 12. Different types of stinger completion methods.

Table 2. Predicted result of stinger completion.

\begin{tabular}{ll}
\hline Project & Decrease percent of production \\
\hline 1 & $9.8 \%$ \\
2 & $11.3 \%$ \\
3 & $14.2 \%$ \\
\hline
\end{tabular}

adopted, considering its better effect for water control.

\subsection{Field effect analysis}

In the actual field application, one 160 m' 2-7/8 tubing was equipped in the horizontal section. After that, the water cut gradually decreased, as shown in Fig. 13. In the following year, the water cut of the well reduced by $3 \%-8 \%$, indicating its effect for water control. However, due to the differences between the simulated and actual operating conditions, especially the flowing bottom hole pressure controlled by people for output adjustment, the field application effect was not in fully agreement with theoretical calculation results. It would be expected expected that if the liquid production was limited in a relatively low level, the water cut would be lower. This technology not only improves the productivity of the wells, but also increases the longevity.

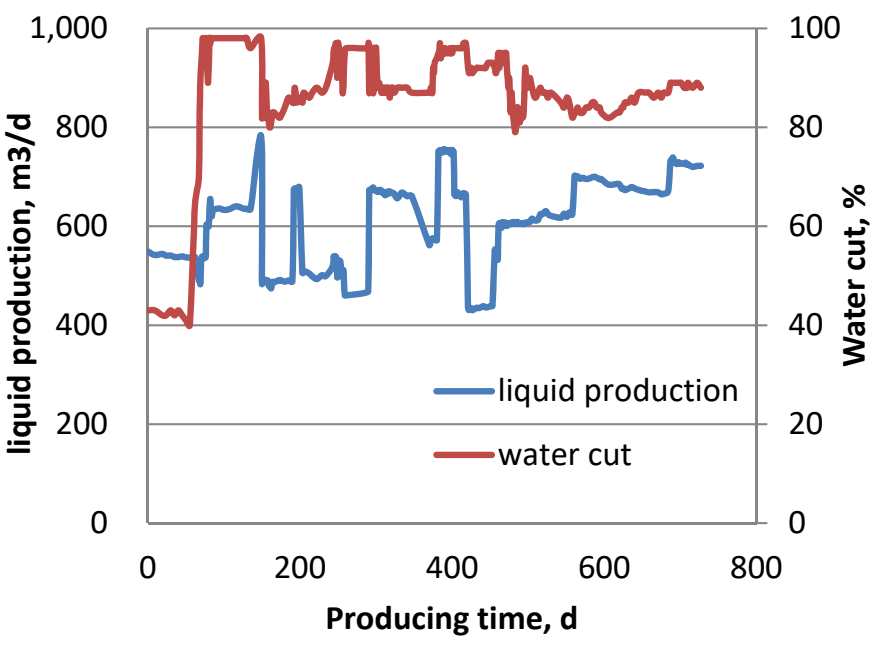

Fig. 13. Production performance of the well.

The common stinger completion and improved technology have been used in Bohai oil fields for more than 5 wells, and the results are promising. A combination of stinger completion and chemical method is also under investigation for a better performance. 


\section{Discussion}

Compared with other mechanical and chemical technologies, the method introduced in this paper is much simpler. Moreover, the operation of inserting central tubing can be finished during routine pump inspection. This means that this technology does not need additional operation time, which is important for offshore wells. This is also one of the most important reasons why stinger completion is chosen for this well. However, since it is really difficult to determine the water cut in each part of the horizontal well, no exact result of water cut changes after inserting central tubing could be predicted. Only decrease percent of production could be predicted after setting different types and lengths of central tubing.

Stinger completion is a passive method for water control, thus its effect is negligible especially when wells need to produce at higher liquid production. So, a new kind of intelligent phase control valve is implemented now. This phase control valve is expected suitable for both early completion phase and wells with high water cut. What's more, combined application of mechanical and chemical methods is also proposed to improve the development result of offshore horizontal wells.

\section{Conclusion}

Bottom water coning has been a serious problem for horizontal wells in the Bohai oil fields. Both mechanical and chemical methods are studied to inhibit the rapid rise of water cut. Stinger completion and the improved stinger completion are one of the methods applied for water control in recent years.

The calculating results of the new mathematical model show that inserting central pipe in the horizontal section can effectively improve the inflow profile of the wellbore. The results of field application show that this technology can achieve the purpose of controlling water cut.

\section{Nomenclature}

$\phi(x, y, z)=$ potential function

$Q=$ liquid production rate of the well, $\mathrm{m}^{3} / \mathrm{d}$

$L=$ length of horizontal section, $\mathrm{m}$

$x_{1}=$ abscissa of the heel of the horizontal section

$x_{2}=$ abscissa of the finger of the horizontal section

$z_{w}=$ distance of the horizontal section to the $\mathrm{x}-\mathrm{y}$ plane, $\mathrm{m}$

$q_{i}=$ liquid production of segment $i, \mathrm{~m}^{3} / \mathrm{d}$

$L_{1}=$ length of segment $i, \mathrm{~m}$

$h=$ reservoir thickness, $\mathrm{m}$

$p_{e}=$ pressure of the constant pressure boundary, $\mathrm{MPa}$

$\theta=$ hole deviation angle, ${ }^{\circ}$

$\rho=$ density of the produced liquid, $\mathrm{g} / \mathrm{cm}^{3}$

$f=$ coefficient of friction resistance

$D=$ inner diameter of the wellbore, $\mathrm{mm}$ $\mathrm{m}^{3} / \mathrm{d}$

$Q_{i}=$ liquid volume flowing through the end of segment $i$,

\section{Acknowledgments}

This research was conducted under the support of the
National Science and Technology Major Project of China (Grant No. 2016ZX05058-003).

Open Access This article is distributed under the terms and conditions of the Creative Commons Attribution (CC BY-NC-ND) license, which permits unrestricted use, distribution, and reproduction in any medium, provided the original work is properly cited.

\section{References}

Abdulmohsin, I., Wang, Z., Bai, B. The plugging performance of preformed particle gel to water flow through large opening void space conduits. J. Pet. Sci. Eng. 2017, 156: 51-61.

Adesina, F., Paul, A., Oyinkepreye, O., et al. An improved model for estimating productivity of horizontal drain hole. Paper SPE 184264 Presented at SPE Nigeria Annual International Conference and Exhibition, Lagos, Nigeria, 2-4 August, 2016.

Amini, S., Valkó, P.P. Using distributed volumetric sources to predict production from multiple-fractured horizontal wells under non-Darcy-flow conditions. SPE J. 2010, 15(1): 105-115.

Augustine, J.R. An Investigation of the economic benefit of inflow control devices on horizontal well completions using a reservoir-wellbore coupled model. Paper SPE 78293 Presented at European Petroleum Conference, Aberdeen, United Kingdom, 29-31 October, 2002.

Augustine, J.R., McIntyre, A., Adam, R.J., et al. Increasing oil recovery by preventing early water and gas breakthrough in a west brae horizontal well: A case history. Paper SPE 99718 Presented at SPE /DOE Symposium on Improved Oil Recovery, Tulsa, Oklahoma, USA, 22-26 April, 2006.

Brekke, K., Lien, S.C. New and simple completion methods for horizontal wells improve production performance in high-permeability, thin oil zones. SPE Drill. Completion 1994, 9(3): 205-209.

Cheng, L., Lan, J. The method of reservoir numerical simulation when considering the pressure drop alone the horizontal well-bore. Acta Petrolei Sinica 2002, 23(1): 67-71. (in Chinese)

Fu, L., Zhang, G., Ge, J., et al. Study on a new waterinhibiting and oil-increasing proppant for bottom-waterdrive reservoirs. J. Pet. Sci. Eng. 2016, 145: 290-297.

Furui, K., Zhu, D., Hill, A.D. A rigorous formation damage skin factor and reservoir inflow model for a horizontal well. SPE Prod. Fac. 2002, 18(3): 151-157.

Gomez, M., Anaya, A.F., Araujo, Y.E., et al. Passive inflow control device (ICDs) application in a horizontal wells completions in the rubiales area heavy-oil reservoir. Paper SPE 171040 Presented at the SPE Heavy and Extra Heavy Oil Conference: Latin America, Medllín, Colombia, 2426 September, 2014.

Hasan, A.R., Kabir, C.S. Modeling two-phase fluid and heat flows in geothermal wells. J. Pet. Sci. Eng. 2009, 71(12): 77-86.

Hill, A.D., Zhu, D. The relative importance of wellbore pressure drop and formation damage in horizontal wells. Paper SPE 100207 Presented at the SPE Europec/EAGE 
Annual Conference and Exhibition, Vienna, Austria, 1215 June, 2006.

Jansen., J.D. A semianalytical model for calculating pressure drop along horizontal wells with stinger completions. SPE J. 2003, 8(2): 138-146.

Jansen, J.D., Wagenvoor, A.M., Droppert, V.S., et al. Smart well solutions for thin oil rims: Inflow switching and the smart stinger completion. Paper SPE 77942 Presented at the SPE Asia Pacific Oil and Gas Conference and Exhibition, Melbourne, Australia, 8-10 October, 2002.

Johansen, T.E., Khoriakov, V. Iterative techniques in modeling of multi-phase flow in advanced wells and the near well region. J. Pet. Sci. Eng. 2007, 58(1-2): 49-67.

Khoriakov, V., Johansen, A.C., Johansen, T.E. Transient flow modeling of advanced wells. J. Pet. Sci. Eng. 2012, 86: 99-110.

Li, Z., Fernandes, P.X., Zhu, D. Understanding the roles of inflow-control devices in optimizing horizontal-well performance. SPE Drill. Completion 2011, 26(3): 376385.

Liu, X., Guo, C., Jiang, Z., et al. The model coupling fluid flow in the reservoir with flow in the horizontal wellbore. Acta Petrolei Sinica 1999, 20(3): 82-86. (in Chinese)

Liu, X., Zhang, Z., Liu, X., et al. A model to calculate pressure drops of horizontal wellbore variable mass flow coupled with flow in a reservoir. Journal of Southwest Petroleum Institute 2000, 22(2): 36-39. (in Chinese)

Luo, W., Li, H., Wang, Y., et al. A new semi-analytical model for predicting the performance of horizontal wells completed by inflow control devices in bottom-water reservoirs. J. Nat. Gas Sci. Eng. 2015, 27: 1328-1339.

Ma, Y., Yi, X. A new discovery about inflow control devices in controlling water and increasing oil recovery. J. Pet. Sci. Technol. 2017, 7(4): 32-40.

Naderi, M., Rostami, B., Khosravi, M. Effect of heterogeneity on the productivity of vertical, deviated and horizontal wells in water drive gas reservoirs. J. Nat. Gas Sci. Eng. 2015, 23: 481-491.

Ouyang, L., Huang, W. A comprehensive evaluation of wellcompletion impacts on the performance of horizontal and multilateral wells. Paper SPE 96530 Presented at SPE Annual Technical Conference and Exhibition, Dallas, Texas, 9-12 October, 2005.

Permadi, P., Wibowo, W., Alamsyah, Y., et al. Horizontal well completion with stinger for reducing water problems. Paper SPE 37464 Presented at the SPE Production Operations Symposium, Oklahoma City, Oklahoma, 9-11
March, 1997.

Shuai, C., Duan, Y., Ran, L., et al. Research on the method of controlling bottom water with Inflow Control Devices (ICD) in horizontal well. Oil Drilling \& Production Technology 2012, 34(1): 85-88. (in Chinese)

Sierra, L., East, L., Soliman, M.Y., et al. New completion methodology to improve oil recovery and minimize water intrusion in reservoirs subject to water injection. SPE J. 2011, 16(3): 648-661.

Souza, G.D., Pires, A.P., Abreu, E.D. Well-reservoir coupling on the numerical simulation of horizontal wells in gas reservoirs. Paper SPE 169386 Presented at Latin America and Caribbean Petroleum Engineering Conference, Maracaibo, Venezuela, 21-23 May, 2014.

Szanyi, M.L., Hemmingsen, C.S., Yan, W., et al. Nearwellbore modeling of a horizontal well with computational fluid dynamics. J. Pet. Sci. Eng. 2018, 160: 119-128.

Vicente, R., Sarica, C., Ertekin, T. A numerical model coupling reservoir and horizontal well flow dynamics: Transient behavior of single-phase liquid and gas flow. Paper SPE 65508 Presented at SPE /CIM International Conference on Horizontal Well Technology, Calgary, Alberta, Canada, 6-8 November, 2000.

Wang, H., Xue, S., Gao, C., et al. Profile control method for perforated horizontal wells in heterogeneous reservoirs. Journal of China University of Petroleum 2012, 36(3): 135-139. (in Chinese)

Wang, J., Liu, H., Liu, Y., et al. Mechanism and sensitivity analysis of an inflow control devices (ICDs) for reducing water production in heterogeneous oil reservoir with bottom water. J. Pet. Sci. Eng. 2016, 146: 971-982.

Wang, J., Liu, Y., Yang, Z., et al. Research progress on water breakthrough mechanism for horizontal wells. Special Oil \& Gas Reservoirs 2010, 17(1): 6-10. (in Chinese)

Wolfsteiner, C., Durlofsky, L.J., Aziz, K. Approximate model for productivity of nonconventional wells in heterogeneous reservoirs. SPE J. 2000, 5(2): 218-226.

Xiong, Y., Luo, D., Tang, H., et al. New type horizontal well completion method of delaying and controlling bottom water coning. Journal of Southwest Petroleum Institute 2009, 31(1): 103-106. (in Chinese)

Zhang, S., Li, H., Yang, S., et al. Influx and pressure performance prediction of stinger completion in horizontal well. Drill. Prod. Technol. 2009, 32(6): 43-45. (in Chinese) 